\title{
Highly active and durable FeNiCo oxyhydroxide OER electrocatalysts derived from fluoride precursors
}

Masahiro Nishimoto, Sho Kitano, ${ }^{\dagger}$ Damian Kowalski, ${ }^{\dagger}$ Yoshitaka Aoki ${ }^{\dagger}$ and Hiroki

Habazakit,*

Graduate School of Chemical Sciences and Engineering, Hokkaido University, North 13, West 8, Sapporo, Hokkaido 060-8628, Japan

'Division of Applied Chemistry, Faculty of Engineering, Hokkaido University, North 13, West 8, Sapporo, Hokkaido 060-8628, Japan

*Corresponding author: habazaki@eng.hokudai.ac.jp (Hiroki Habazaki)

Number of pages: $\quad 5$

Number of figures: $\quad 4$ 

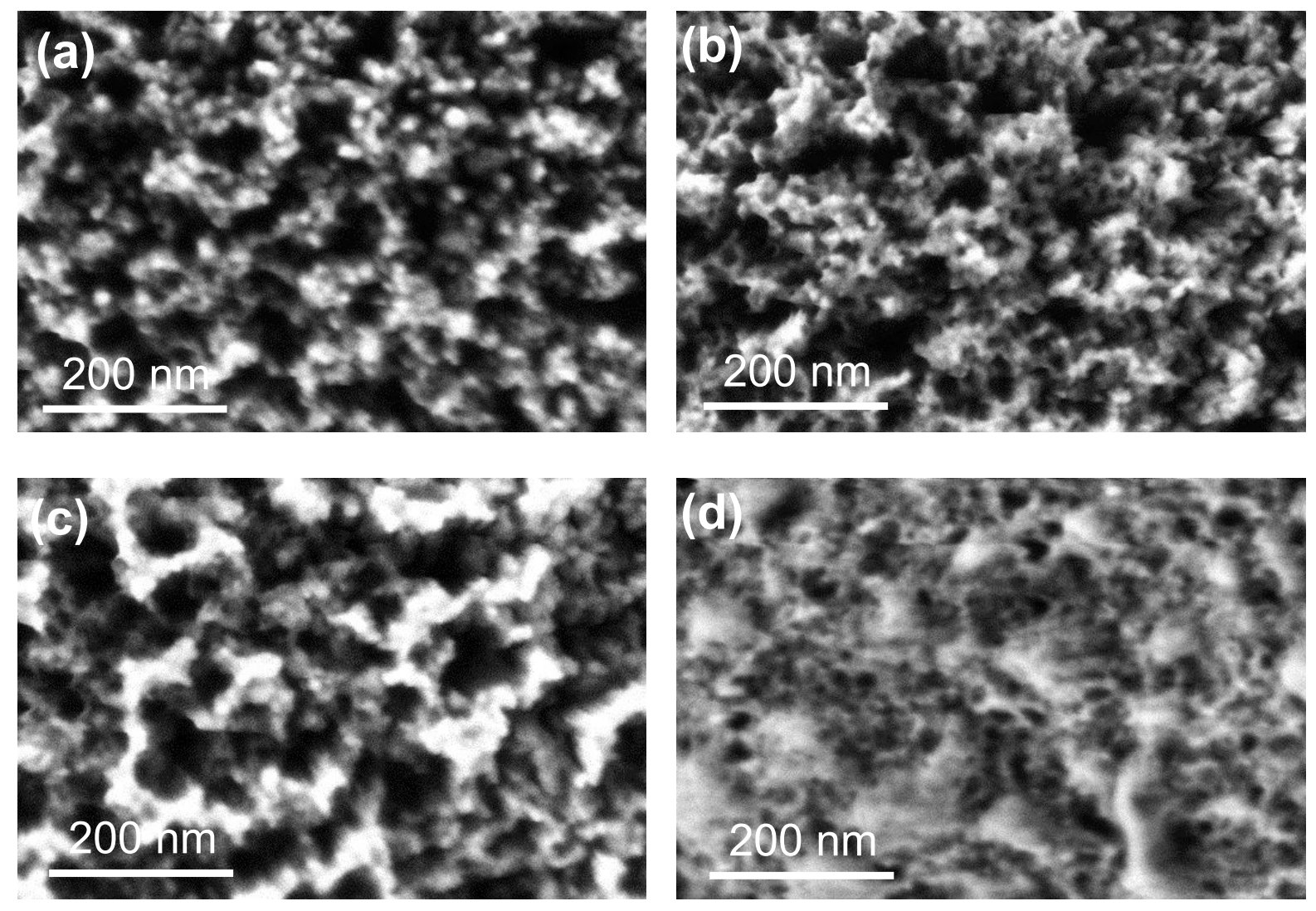

Figure S1. Scanning electron micrographs of FeNiCo alloy anodized at $50 \mathrm{~mA} \mathrm{~cm}^{-2}$ for (a) 70, (b) 250, (c) 400, and (d) $7200 \mathrm{~s}$. 


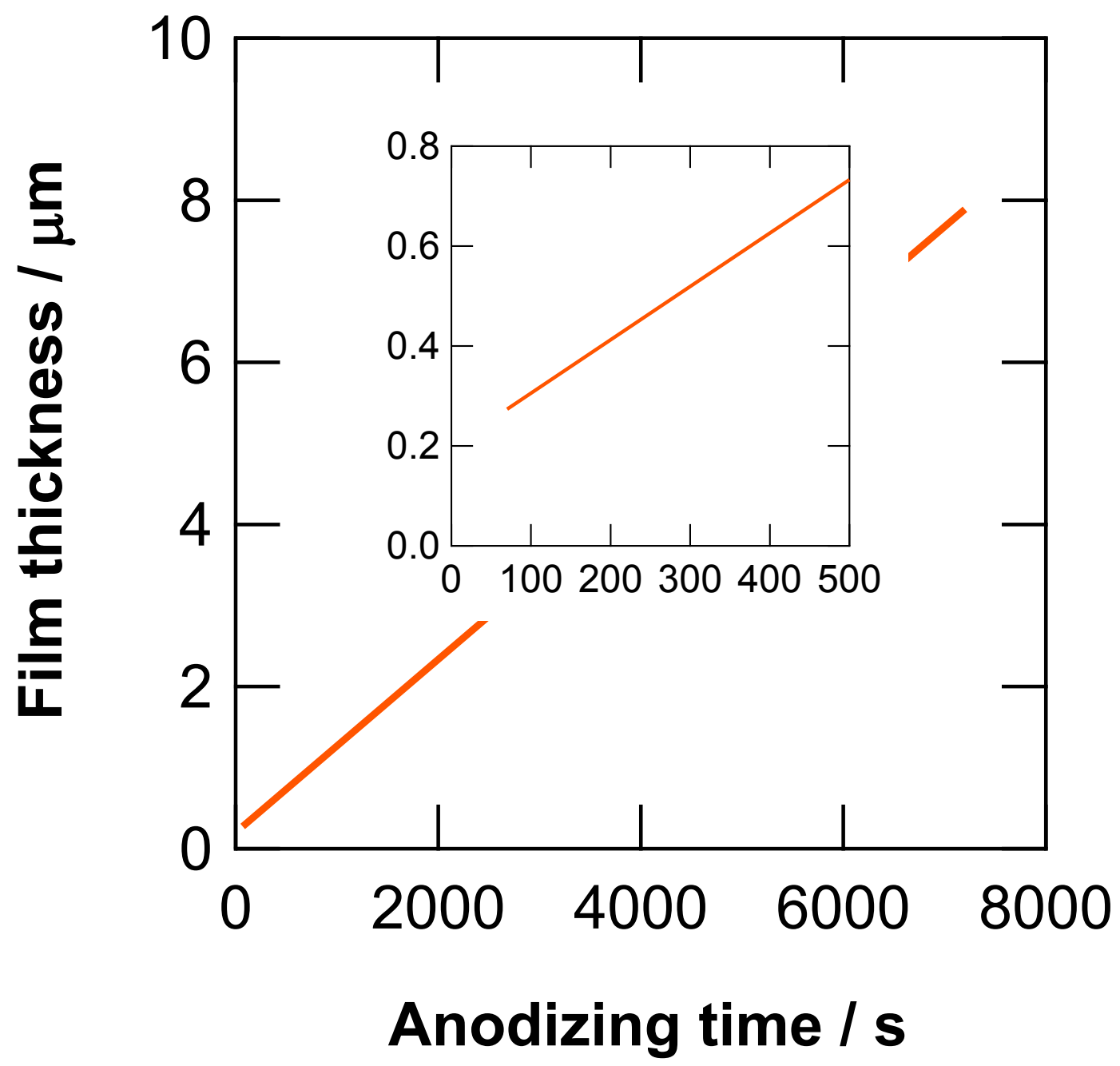

Figure S2. Change in thickness of porous layer with anodizing time during anodizing of the FeNiCo alloy at $50 \mathrm{~mA} \mathrm{~cm}^{-2}$. 

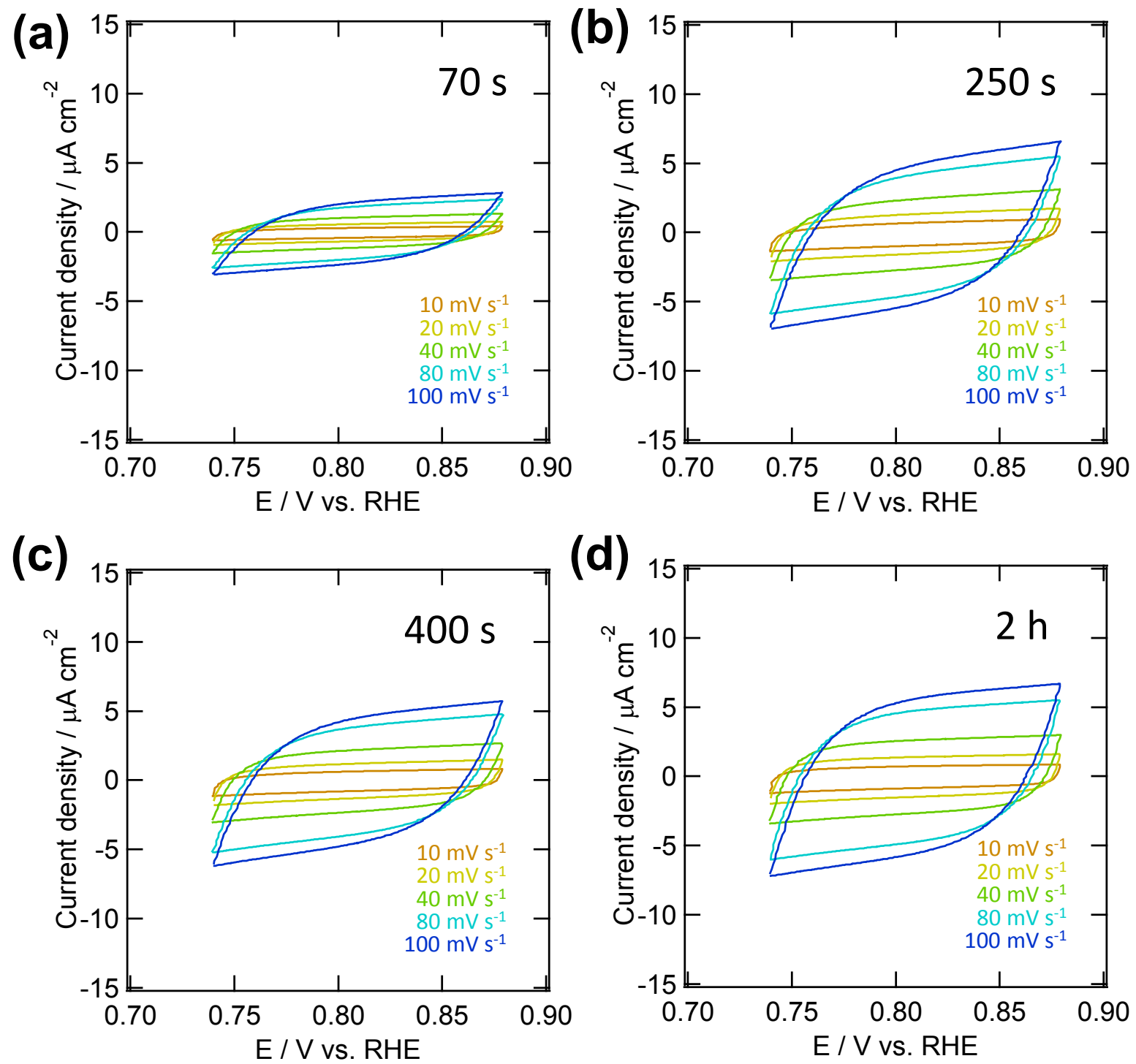

Figure S3. CV curves of the FeCoNi alloy, anodized for (a) $70 \mathrm{~s}$, (b) $250 \mathrm{~s}$, (c) $400 \mathrm{~s}$, (d) $2 \mathrm{~h}$, measured in $0.1 \mathrm{~mol} \mathrm{dm}^{-3} \mathrm{KOH}$ electrolyte at several sweep rates. 

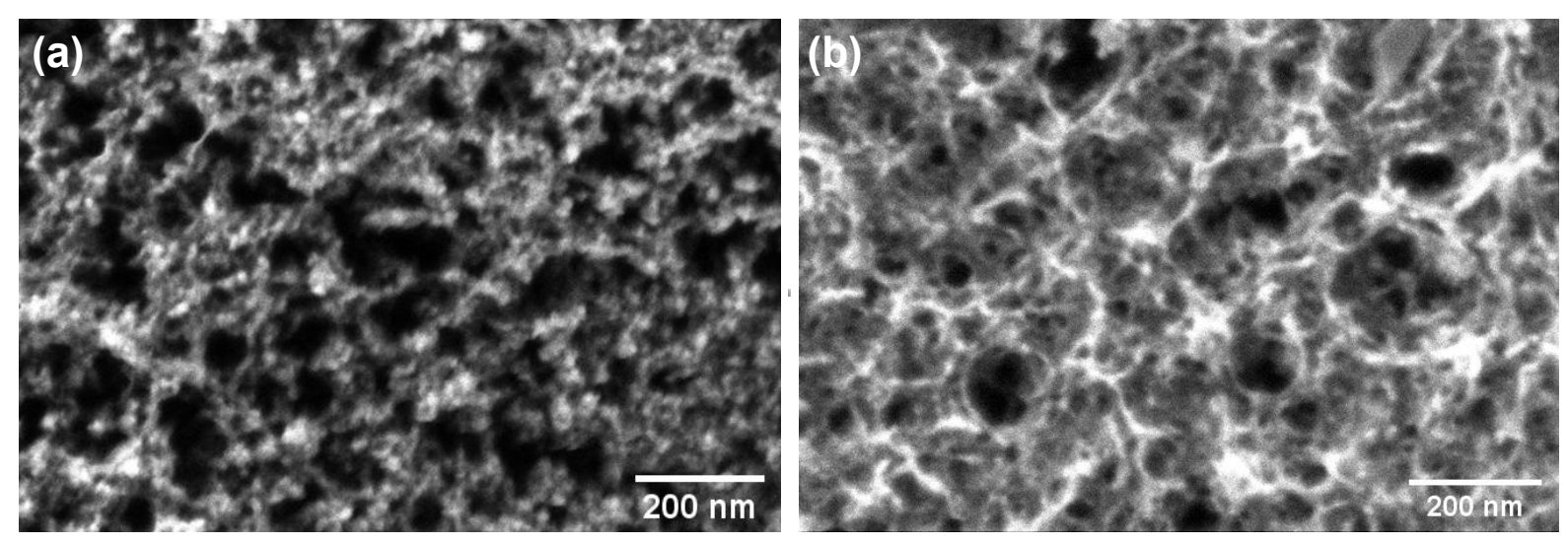

Figure S4. Scanning electron micrographs of the anodized FeNiCo electrode after (a) five CV cycles and (b) the durability test. 